Article

\title{
Surface Morphology-Dependent Functionality of Titanium Dioxide-Nickel Oxide Nanocomposite Semiconductors
}

\author{
Yuan-Chang Liang *, Nian-Cih Xu and Kai-Jen Chiang \\ Department of Optoelectronics and Materials Technology, National Taiwan Ocean University, \\ Keelung 20224, Taiwan; sad821008@gmail.com (N.-C.X.); ssdcjh972003@yahoo.com.tw (K.-J.C.) \\ * Correspondence: yuanvictory@gmail.com or yuan@ntou.edu.tw
}

Received: 28 September 2019; Accepted: 19 November 2019; Published: 21 November 2019

\begin{abstract}
In this study, $\mathrm{TiO}_{2}-\mathrm{NiO}$ heterostructures were synthesized by combining hydrothermal and chemical bath deposition methods. The post-annealing temperature was varied to control the surface features of the $\mathrm{TiO}_{2}-\mathrm{NiO}$ heterostructures. $\mathrm{TiO}_{2}-\mathrm{NiO}$ heterostructures annealed at $350{ }^{\circ} \mathrm{C}$ comprised NiO-nanosheet-decorated $\mathrm{TiO}_{2}$ nanostructures (NST), whereas those annealed at $500^{\circ} \mathrm{C}$ comprised NiO-nanoparticle-decorated $\mathrm{TiO}_{2}$ nanostructures (NPT). The NPT exhibited higher photodegradation activity than the NST in terms of methylene blue (MB) degradation under irradiation. Structural analyses demonstrated that the NPT had a higher surface adsorption capability for MB dyes and superior light-harvesting ability; thus, they exhibited greater photodegradation ability toward MB dyes. In addition, the NST showed high gas-sensing responses compared with the NPT when exposed to acetone vapor. This result was attributable to the higher number of oxygen-deficient regions on the surfaces of the NST, which increased the amount of surface-chemisorbed oxygen species. This resulted in a relatively large resistance variation for the NST when exposed to acetone vapor.
\end{abstract}

Keywords: surface; morphology; semconductors; functionality

\section{Introduction}

$\mathrm{TiO}_{2}$ has been widely studied for applications in photodegradation organic dyes and gas-sensing materials because of its low toxicity, high chemical stability, and environmental friendliness [1-6]. However, $\mathrm{TiO}_{2}$ still has some drawbacks that might limit its efficiency in photocatalyst and gas-sensing materials. The wide band gap of $\mathrm{TiO}_{2}$ limits its ability to absorb visible light; moreover, rapid recombination of photogenerated electron-hole pairs hinders its performance in photodegrading organic dyes [7]. $\mathrm{TiO}_{2}$ has been favored for sensing $\mathrm{H}_{2}, \mathrm{NO}_{2}$, and $\mathrm{C}_{2} \mathrm{H}_{5} \mathrm{OH}$ at elevated temperatures of $290-550{ }^{\circ} \mathrm{C}$ [8]; nevertheless, pure $\mathrm{TiO}_{2}$ with improved gas-sensing response is still highly desired for fabricating gas sensors with high gas detection performance. Recently, constructing $\mathrm{TiO}_{2}$-based heterostructures proved to be a promising approach to enhancing the photodegradation and gas-sensing abilities of $\mathrm{TiO}_{2}$. Several $\mathrm{TiO}_{2}$-based heterostructure systems have been proposed and investigated. Decorating the surface of $\mathrm{TiO}_{2}$ with a CdS photosensitizer improves its photodegradation ability toward rhodamine $\mathrm{B}$ [9]. $\mathrm{SrTiO}_{3} / \mathrm{TiO}_{2}$ heterostructures are beneficial for the rapid separation of photogenerated electrons and holes, and they improve the photodegradation performance of pristine $\mathrm{TiO}_{2}$ [10]. $\mathrm{TiO}_{2}-\mathrm{ZnO}$ composite tubes exhibit higher organic dye photodegradation ability when compared with pristine $\mathrm{TiO}_{2}$ tubes [11]. According to research fabricating $\mathrm{TiO}_{2}$-based heterostructures in applications such as gas-sensing materials, $\mathrm{ZnS}$-sphere-decorated $\mathrm{TiO}_{2}$ flower-like composites exhibit a superior gas-sensing response to pristine $\mathrm{TiO}_{2}$ flowers [3]. Moreover, decorating the surface of $\mathrm{TiO}_{2}$ nanorods with island-like $\mathrm{CdO}$ crystallites markedly improves the gas-sensing response of the 
nanorods to low-concentration $\mathrm{NO}_{2}$ [2]. Increased potential barriers in the heterostructure systems could constitute an essential factor in enhancing the gas-sensing performance of $\mathrm{TiO}_{2}$ on exposure to reducing and oxidizing gases. Accordingly, most proposed $\mathrm{TiO}_{2}$-based heterostructures are based on n-type oxides or sulfides uniformly distributed on the surfaces of n-type $\mathrm{TiO}_{2}$, leading to the formation of n-n-type heterogeneous structures in the composite systems.

However, in addition to $n$-n-type $\mathrm{TiO}_{2}$-based heterogeneous systems, recent efforts have focused on improving the photodegradation and gas-sensing performance of $\mathrm{TiO}_{2}$ with a $\mathrm{p}-\mathrm{n}$-type heterogeneous system. $\mathrm{NiO}$ is a p-type metal-oxide semiconductor with a wide band-gap energy $(\mathrm{Eg}=3.6-4.0 \mathrm{eV})[12]$. Creating $\mathrm{TiO}_{2}-\mathrm{NiO} \mathrm{p}-\mathrm{n}$ heterojunctions is one of the most effective strategies for developing efficient $\mathrm{TiO}_{2}$-based photocatalysts. When p-type $\mathrm{NiO}$ and n-type $\mathrm{TiO}_{2}$ form a $\mathrm{p}-\mathrm{n}$ junction, an inner electric field is established at the interface, which then acts as a potential barrier to prevent the recombination of electrons and holes. Therefore, improved photodegradation performance towards organic dyes is expected for $\mathrm{TiO}_{2}-\mathrm{NiO}$ p-n-type heterostructures [13]. Moreover, p-type $\mathrm{NiO}$ is a suitable catalyst for promoting selective oxidation of various volatile organic compounds [14]. Constructing $\mathrm{TiO}_{2}-\mathrm{NiO}$ heterostructures is also a promising approach to improving both gas-sensing abilities of n-type $\mathrm{TiO}_{2}$ [15]. However, systematic studies on $\mathrm{NiO}$ loading effects on both the photodegradation and gas-sensing properties of $\mathrm{TiO}_{2}$ are still limited in number. In the current study, $\mathrm{TiO}_{2}$ flower-based heterostructures were synthesized and decorated with various $\mathrm{NiO}$ shell layer crystallites. The three-dimensional (3D) architecture of $\mathrm{TiO}_{2}$ nanostructures were used as templates to fabricating $\mathrm{TiO}_{2}-\mathrm{NiO}$ nanocomposites herein. This is due to the fact that 3D nanotechnology of oxides has been demonstrated to obtain remarkable properties and multifunctionality [16]. Controlling the post-annealing procedure resulted in two types of $\mathrm{TiO}_{2}-\mathrm{NiO}$ composites-namely $\mathrm{NiO}$ nanosheet-decorated $\mathrm{TiO}_{2}$ flowers and $\mathrm{NiO}$ nanoparticle-decorated $\mathrm{TiO}_{2}$ nanostructures - that were used to understand the effects of different morphologies and microstructures on photodegradation ability and gas-sensing responses. This study proposes a correlation between the microstructures of the $\mathrm{NiO}$ shell layer and the photodegradation and gas-sensing performance of the $\mathrm{TiO}_{2}-\mathrm{NiO}$ composites. The investigations herein are important for designing $\mathrm{TiO}_{2}-\mathrm{NiO}$ nanocomposites in photodegrading organic dyes and gas-sensing applications with satisfactory performance.

\section{Materials and Methods}

In this study, the $\mathrm{TiO}_{2}$ nanostructures were grown on glass substrates using a hydrothermal method. For hydrothermal synthesis, $2.4 \mathrm{~mL}$ of deionized water was mixed with $3.6 \mathrm{~mL}$ of concentrated $\mathrm{HCl}(35 \%)$ in a Teflon-lined stainless autoclave. The mixture was stirred at ambient conditions for $5 \mathrm{~min}$ and after that, $0.25 \mathrm{~mL}$ of $\mathrm{TiCl}_{4}$ was added into the mixed solution for preparation of $\mathrm{TiO}_{2}$ nanostructures. The hydrothermal synthesis was conducted at $180{ }^{\circ} \mathrm{C}$ for $3 \mathrm{~h}$. NiO crystallites were decorated onto the surfaces of $\mathrm{TiO}_{2}$ nanostructures by a chemical bath deposition (CBD) method. The solution for CBD process was prepared by adding $1 \mathrm{~mL}$ of aqueous ammonia (25-28\%) to the mixture of $20 \mathrm{~mL}$ of $1 \mathrm{M}$ nickel sulfate and $16 \mathrm{~mL}$ of $0.25 \mathrm{M}$ potassium persulfate. The $\mathrm{TiO}_{2}$ nanostructures were immersed into the CBD solution for reaction and the samples were rinsed with distilled water. Finally, the as-synthesized samples were post-annealed at 350 and $500{ }^{\circ} \mathrm{C}$ in ambient air for $1 \mathrm{~h}$ to fabricate the $\mathrm{TiO}_{2}-\mathrm{NiO}$ heterostructures with various surface crystal features. Notably, the market crystalline temperature of the $\mathrm{NiO}$ phase from initially formed $\mathrm{Ni}$-based hydroxide nanosheets was above $350{ }^{\circ} \mathrm{C}$ in this study. The sample annealed at $350{ }^{\circ} \mathrm{C}$ formed $\mathrm{NiO}$-nanosheet-decorated $\mathrm{TiO}_{2}$ nanostructures (NST); that annealed at $500{ }^{\circ} \mathrm{C}$ formed $\mathrm{NiO}$-nanoparticle-decorated $\mathrm{TiO}_{2}$ nanostructures (NPT). The NST and NPT were used to present the corresponding samples annealed at 350 and $500{ }^{\circ} \mathrm{C}$, respectively.

Crystal structures of the as-synthesized samples were investigated by X-ray diffraction (XRD) using $\mathrm{Cu} \mathrm{K} \alpha$ radiation. The scanning electron microscopy (SEM) was performed to investigate surface morphology of the samples. High-resolution transmission electron microscopy (HRTEM) was used to investigate the detailed microstructures of the $\mathrm{TiO}_{2}-\mathrm{NiO}$ composites. The attached energy dispersive X-ray spectroscopy (EDS) was used to investigate the compositions of the $\mathrm{TiO}_{2}-\mathrm{NiO}$ composite samples. 
X-ray photoelectron spectrometry (XPS) analysis was used to determine the chemical binding status of constituent elements of the samples. The analysis of absorbance spectra of the composites was conducted by using a UV-Vis spectrophotometer. Photodegradation performance of various $\mathrm{TiO}_{2}-\mathrm{NiO}$ composites were performed by comparing the degradation of aqueous solution of methylene blue (MB, $10^{-6} \mathrm{M}$ ) containing various $\mathrm{TiO}_{2}-\mathrm{NiO}$ composites as catalysts under solar light irradiation excited from a $100 \mathrm{~W}$ Xe arc lamp. The variation of MB solution concentration in the presence of various $\mathrm{TiO}_{2}-\mathrm{NiO}$ composites with different irradiation durations was analyzed by recording the changes of absorbance spectra using a UV-Vis spectrophotometer. The gas-sensing response of the gas sensors made from the $\mathrm{TiO}_{2}-\mathrm{NiO}$ composites to acetone vapor with concentrations of $50-750 \mathrm{ppm}$ was defined as the $\mathrm{Rg} / \mathrm{Ra}$. Ra was the sensor electrical resistance in the absence of the target gas and $\mathrm{Rg}$ was that in the target gas.

\section{Results and Discussion}

Figure $1 \mathrm{a}, \mathrm{b}$ depict the SEM images of hydrothermally derived $3 \mathrm{D} \mathrm{TiO}_{2}$ nanostructures. The lengths of the $\mathrm{TiO}_{2}$ petals ranged from 1.2 to $3.1 \mu \mathrm{m}$ and the surface of $\mathrm{TiO}_{2}$ was smooth. The possible growth mechanism of the hydrothermally derived $\mathrm{TiO}_{2}$ nanostructures herein has been reported elsewhere [3]. Figure $1 c$, d illustrate the SEM images of $\mathrm{TiO}_{2}-\mathrm{NiO}$ composites formed through post-annealing at 350 ${ }^{\circ} \mathrm{C}$. The surfaces of the $\mathrm{TiO}_{2}-\mathrm{NiO}$ composites consisted of undulated shell layers and were rough. The coverage of the sheet-like $\mathrm{NiO}$ crystallites on the surfaces of $\mathrm{TiO}_{2}$ nanostructures was uniform, and a homogeneous layer-like structure was thus formed. The sheet thickness of the $\mathrm{NiO}$ crystallites ranged from 10 to $25 \mathrm{~nm}$. When the post-annealing temperature was further increased to $500{ }^{\circ} \mathrm{C}$, the morphology of the $\mathrm{NiO}$ crystallites decorated on the surfaces of the $\mathrm{TiO}_{2}$ structures markedly differed from that observed at $350{ }^{\circ} \mathrm{C}$ (Figure 1e,f). Comparatively, the surface morphology of the $\mathrm{NiO}$ thin layer on the $\mathrm{TiO}_{2}$ surface became a discontinuous shell structure when the $\mathrm{TiO}_{2}-\mathrm{NiO}$ composites were formed at $500{ }^{\circ} \mathrm{C}$. According to the SEM observations, the morphology of $\mathrm{TiO}_{2}-\mathrm{NiO}$ composites can be controlled by changing the post-annealing temperature. Figure $2 \mathrm{a}, \mathrm{b}$ illustrate the XRD patterns of the $\mathrm{TiO}_{2}$-based composites with various thermal post-annealing procedures. Several sharp and intense Bragg reflections originating from the rutile $\mathrm{TiO}_{2}$ phase (JCPDS No. 004-0551) were observed (Figure $2 \mathrm{a}, \mathrm{b}$ ). The $\mathrm{TiO}_{2}$ nanostructures were highly crystalline, as revealed by the XRD patterns. In addition to the Bragg reflections originating from the $\mathrm{TiO}_{2}$ phase (Figure 2a,b), a tiny Bragg reflection centered at approximately $43.4^{\circ}$ was observed and was ascribed to the (200) plane of the cubic $\mathrm{NiO}$ structure (JCPDS No. 02-1216) [17]. No Bragg reflections from other impurities were detected. The SEM and XRD results demonstrated that crystalline $\mathrm{TiO}_{2}-\mathrm{NiO}$ composites with various $\mathrm{NiO}$ shell layer morphologies could be formed through various post-annealing procedures.

Figure 3 a displays the low-magnification TEM image of a single $\mathrm{TiO}_{2}-\mathrm{NiO}$ composite formed at $350{ }^{\circ} \mathrm{C}$. For a representative core-shell structure, a single $\mathrm{TiO}_{2}$ petal was uniformly covered with interconnected thin $\mathrm{NiO}$ sheets when the as-synthesized composite was annealed at $350{ }^{\circ} \mathrm{C}$. Figure $3 \mathrm{~b}$ shows distinct boundaries between the adjacent sheet-like $\mathrm{NiO}$ crystallites. As revealed by the HRTEM image depicted in Figure 3c, lattice fringes with multiple orientations were observed in the $\mathrm{NiO}$ crystallites, revealing a polycrystalline feature. Moreover, lattice fringes with an interval of $0.20 \pm 0.02$ $\mathrm{nm}$ were determined to correspond to the interplanar distance of $\mathrm{NiO}(200)$. Selected area electron diffraction (SAED) patterns of several NST composites were recorded, as shown in Figure 3d. The patterns exhibited several distinct diffraction rings consisting of sharp and bright spots that originated from the $\mathrm{TiO}_{2}$ petals and $\mathrm{NiO}$ sheets (Figure 3d). According to the SAED patterns, the (110), (101), (200), (111), (210), and (211) crystallographic planes were determined to correspond to the rutile $\mathrm{TiO}_{2}$ phase and the (200) crystallographic plane was determined to correspond to the cubic $\mathrm{NiO}$ phase. EDS line-scan analysis (Figure 3e) confirmed the localization of $\mathrm{Ti}$ in the core area and the tendency of the Ni element to be distributed along the surface of the $\mathrm{TiO}_{2}$ petal, revealing that the $\mathrm{NiO}$ sheets adequately covered the $\mathrm{TiO}_{2}$ surface. By contrast, the TEM images in Figure 3f,g reveal the morphology of the $\mathrm{TiO}_{2}-\mathrm{NiO}$ composite formed at $500^{\circ} \mathrm{C}$ to differ from that of the composite annealed at $350{ }^{\circ} \mathrm{C}$. NiO crystallites with a particle-like feature discontinuously decorated the surface of the $\mathrm{TiO}_{2}$ petal. As 
demonstrated by the HRTEM image in Figure 3h, the NiO particles had a diameter of 10 to $18 \mathrm{~nm}$. The NPT formed at $500{ }^{\circ} \mathrm{C}$ exhibited appropriate crystalline phases (Figure 3i). The corresponding EDS analyses (Figure 3j,k) demonstrated that $\mathrm{Ti}, \mathrm{Ni}$, and $\mathrm{O}$ were the main constituent elements of the composites; moreover, no impurity atoms were detected. The Ni/Ti wt \% ratios of the NPT and NST were 0.68 and 0.73 , respectively in this study.
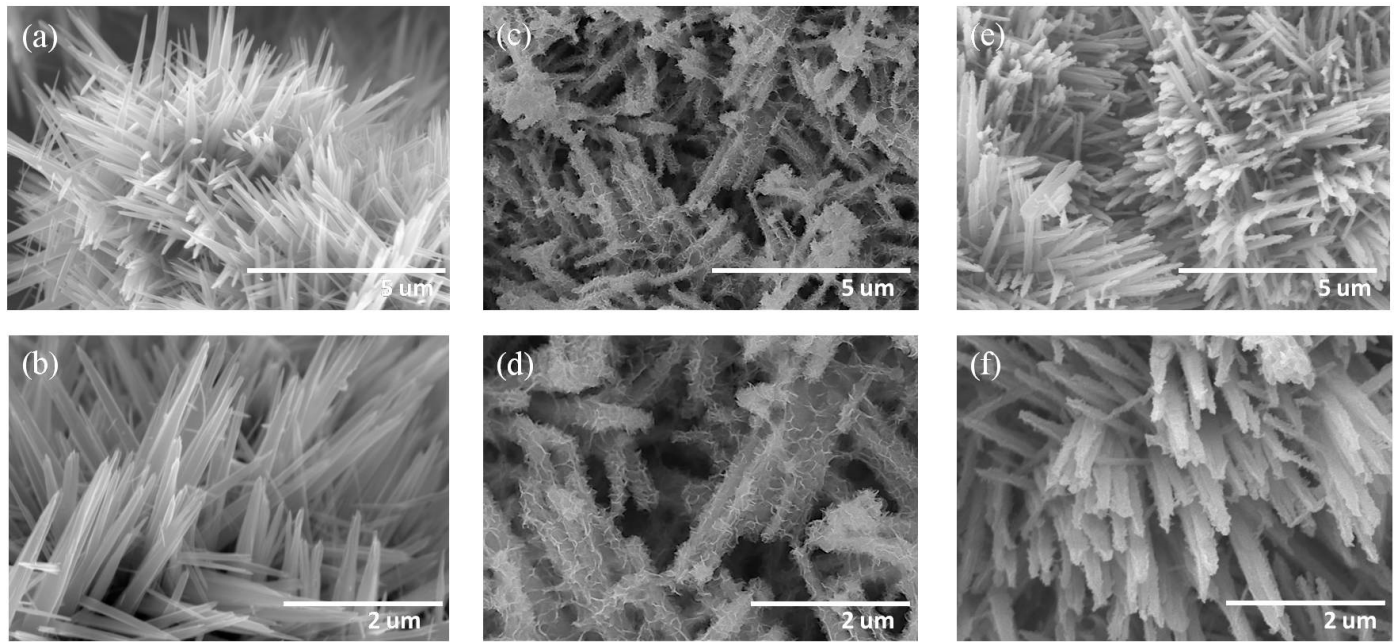

Figure 1. (a,b) Low- and high-magnification SEM images of $\mathrm{TiO}_{2}$ nanostructures. (c,d) Lowand high-magnification SEM images of $\mathrm{TiO}_{2}-\mathrm{NiO}$ composites formed at $350{ }^{\circ} \mathrm{C}$. (e,f) Low- and high-magnification SEM images of $\mathrm{TiO}_{2}-\mathrm{NiO}$ composites formed at $500{ }^{\circ} \mathrm{C}$.

(a)

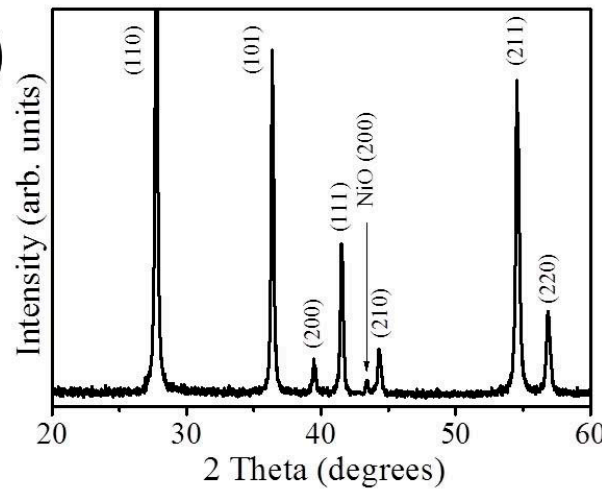

(b)

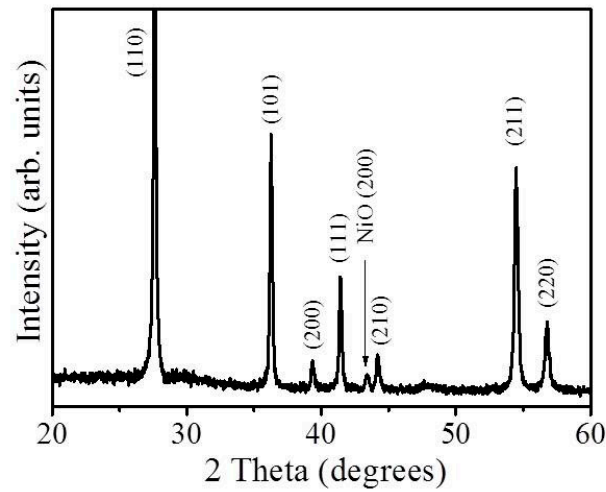

Figure 2. $\mathrm{XRD}$ patterns of $\mathrm{TiO}_{2}-\mathrm{NiO}$ composites formed at (a) $350{ }^{\circ} \mathrm{C}$ and (b) $500{ }^{\circ} \mathrm{C}$. The arrow represents the position of $\mathrm{NiO}$ Bragg reflection.

Figure $4 \mathrm{a}, \mathrm{b}$ show the XPS narrow-scan spectra of the $\mathrm{Ni} 2 \mathrm{p}$ region of the $\mathrm{TiO}_{2}-\mathrm{NiO}$ composites formed at $350{ }^{\circ} \mathrm{C}$ and $500{ }^{\circ} \mathrm{C}$, respectively. The $\mathrm{Ni} 2 \mathrm{p}$ states of the $\mathrm{NiO}$ shell layers (Figure $4 \mathrm{a}, \mathrm{b}$ ) contained multiple peaks at binding energies between 854 and $879 \mathrm{eV}$, including main peaks and satellites. The main peaks of $\mathrm{Ni} 2 \mathrm{p}_{3 / 2}$ and $\mathrm{Ni} 2 \mathrm{p}_{1 / 2}$ were located at approximately 854.1 and $871.8 \mathrm{eV}$, respectively (Figure $4 a, b)$, which were in agreement with those reported in the literature for the $\mathrm{NiO}$ phase $[18,19]$. Figure $4 \mathrm{c}, \mathrm{d}$ show the $\mathrm{O} 1 \mathrm{~s}$ spectra of the $\mathrm{TiO}_{2}-\mathrm{NiO}$ composites formed at $350{ }^{\circ} \mathrm{C}$ and $500{ }^{\circ} \mathrm{C}$, respectively. Sharp fitted subpeaks were observed at a binding energy of approximately 528.8 $\mathrm{eV}$ and were attributed to the lattice oxygen of the $\mathrm{NiO}$ phase [20]; additionally, broadened subpeaks were observed at $530.7 \mathrm{eV}$ and were attributed to the formation of surface-oxygen-deficient sites and surface chemisorbed oxygen species on the $\mathrm{NiO}$ shell layer [21]. Notably, the relative intensity of the higher binding energy component in the $\mathrm{O} 1 \mathrm{~s}$ spectra of the $\mathrm{TiO}_{2}-\mathrm{NiO}$ composites decreased when the composites were thermally treated from $350{ }^{\circ} \mathrm{C}$ to $500{ }^{\circ} \mathrm{C}$. This finding reveals that surface crystalline imperfections of a larger size were formed in the $\mathrm{NiO}$ nanosheets. 

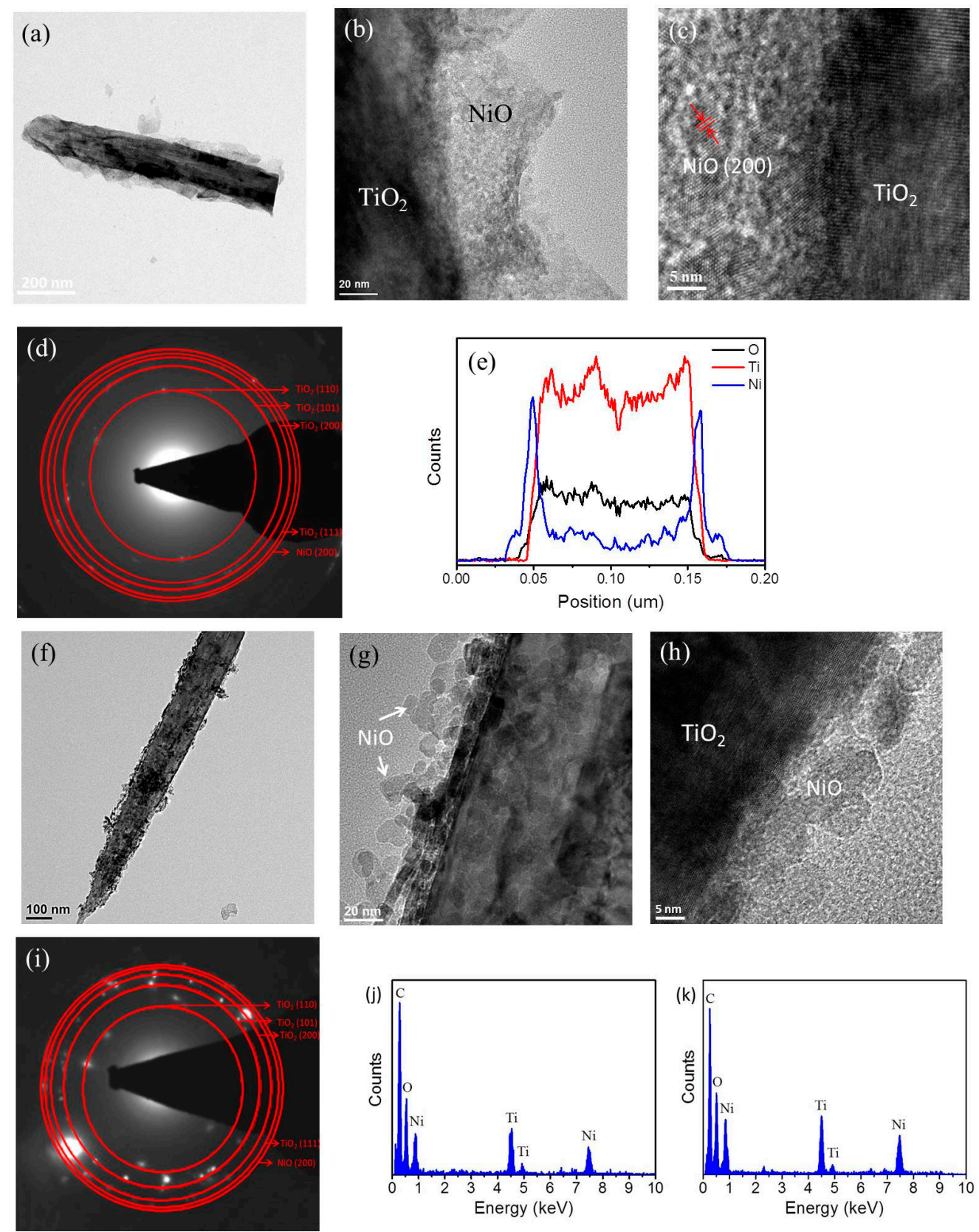

Figure 3. TEM analyses of $\mathrm{TiO}_{2}-\mathrm{NiO}$ composites formed at $350{ }^{\circ} \mathrm{C}$ : (a) Low-magnification TEM image of a single $\mathrm{TiO}_{2}-\mathrm{NiO}$ composite. (b) High-magnification TEM image taken from the $\mathrm{TiO}_{2}-\mathrm{NiO}$ composite. (c) High-resolution transmission electron microscopy (HRTEM) image taken from the local region of the $\mathrm{TiO}_{2}-\mathrm{NiO}$ composite. (d) Selected area electron diffraction (SAED) pattern of several $\mathrm{TiO}_{2}-\mathrm{NiO}$ composites. (e) Energy dispersive X-ray spectroscopy (EDS) line-scanning profiles of the $\mathrm{TiO}_{2}-\mathrm{NiO}$ composite. TEM analyses of $\mathrm{TiO}_{2}-\mathrm{NiO}$ composites formed at $500{ }^{\circ} \mathrm{C}$. (f,g) Low- and high-magnification TEM images of a single $\mathrm{TiO}_{2}-\mathrm{NiO}$ composite, respectively. (h) HRTEM image taken from the local region of the $\mathrm{TiO}_{2}-\mathrm{NiO}$ composite. (i) $\mathrm{SAED}$ pattern of several $\mathrm{TiO}_{2}-\mathrm{NiO}$ composites. ( $\left.\mathbf{j}, \mathbf{k}\right)$ EDS spectra of the NiO-nanoparticle-decorated $\mathrm{TiO}_{2}$ nanostructures (NPT) and NiO-nanosheet-decorated $\mathrm{TiO}_{2}$ nanostructures (NST) composites, respectively. 

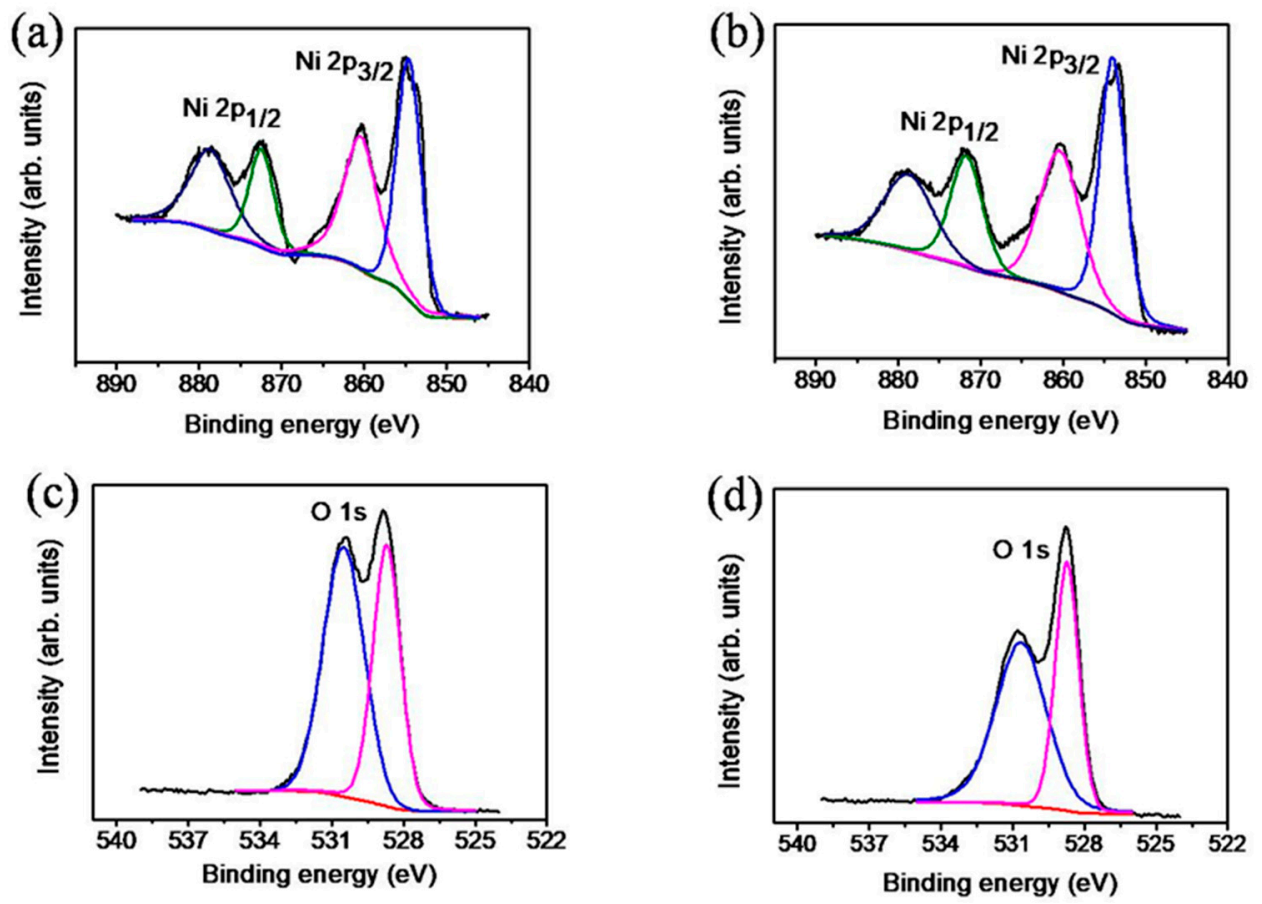

Figure 4. High-resolution XPS spectra in $\mathrm{Ni} 2 \mathrm{p}$ region of $\mathrm{TiO}_{2}-\mathrm{NiO}$ composites formed at various temperatures: (a) $350{ }^{\circ} \mathrm{C}$ and (b) $500{ }^{\circ} \mathrm{C}$. High-resolution XPS spectra in $\mathrm{O}$ 1s region of $\mathrm{TiO}_{2}-\mathrm{NiO}$ composites formed at various temperatures: (c) $350{ }^{\circ} \mathrm{C}$ and (d) $500{ }^{\circ} \mathrm{C}$.

Figure 5 presents the optical absorption properties of the pristine $\mathrm{TiO}_{2}, \mathrm{NST}$, and NPT. For the $\mathrm{TiO}_{2}$, a sharp drop of the absorption edge was observed, and the onset was at approximately $406 \mathrm{~nm}$, which is consistent with the intrinsic band-gap absorption of rutile $\mathrm{TiO}_{2}$ [22]. After the $\mathrm{NiO}$ nanosheets and nanoparticles were coated onto the surfaces of the $\mathrm{TiO}_{2}$ nanostructures, the absorption edge broadened, and a redshift extension in the absorption edge was observed. The extended absorption edge of the $\mathrm{TiO}_{2}-\mathrm{NiO}$ composites suggests strong contact between $\mathrm{NiO}$ and $\mathrm{TiO}_{2}$ engendered by the interdispersion of two semiconductors [7]. In the interface region, the overlap of the conduction band due to the Ti d orbital of titanium oxide and $\mathrm{Ni} d$ orbital of nickel oxide may reduce the energy gap between the Ti $\mathrm{d}$ and $\mathrm{O}$ p orbitals of titanium oxide and enable a redshift of the adsorption edge [23]. Comparatively, the NPT exhibited a higher light harvesting ability. The extension of the optical absorption edge to the visible light region of the $\mathrm{TiO}_{2}-\mathrm{NiO}$ composites can enhance the efficiency of forming electron-hole pairs on the composite photocatalyst surfaces under illumination and might improve the photodegradation performance of the $\mathrm{TiO}_{2}$ nanostructures [7]. A similar redshift of $\mathrm{TiO}_{2}$ adsorption edge because of the surface decoration of $\mathrm{NiO}$ crystals has been shown in other $\mathrm{TiO}_{2}-\mathrm{NiO}$ composites synthesized via sol-gel and electroplating methods [24,25].

The photodegradation performance of the various $\mathrm{TiO}_{2}-\mathrm{NiO}$ composites was examined in terms of $\mathrm{MB}$ solution degradation. This study monitored the variation of the characteristic absorption intensity (at approximately $663 \mathrm{~nm}$ ) of the $\mathrm{MB}$ solution containing various $\mathrm{TiO}_{2}-\mathrm{NiO}$ composites with different irradiation durations, as illustrated in Figure $6 a, b$. The absorbance spectra of the MB solution at $663 \mathrm{~nm}$ decreased with irradiation duration, indicating that the MB dyes were efficiently degraded by the $\mathrm{TiO}_{2}-\mathrm{NiO}$ photocatalysts under irradiation. The photodegradation reaction of the MB solution containing $\mathrm{TiO}_{2}-\mathrm{NiO}$ composites involved the reaction of photoexcited free electrons ( $\mathrm{TiO}_{2}$-core) and holes (NiO-shell) with the $\mathrm{MB}$ solution. This can be understood from the possible band alignment between the $\mathrm{TiO}_{2}$ and $\mathrm{NiO}$ reported previously [26,27]. The subsequently formed hydroxyl radicals in the solution were strong oxidizing agents that effectively decomposed MB dyes [28,29]. The schematic figure of the photodegradation reaction of $\mathrm{TiO}_{2}-\mathrm{NiO}$ towards $\mathrm{MB}$ solution is illustrated in Figure 6c. The absorption intensity of the MB solution containing the NPT decreased more rapidly 
than that of the MB solution containing the NST under the given irradiation duration. Furthermore, the $\mathrm{C} / \mathrm{C}_{\mathrm{o}}$ ratio was used to determine the photodegradation level of the $\mathrm{MB}$ solution containing various composite photocatalysts, where $\mathrm{C}$ represents the remaining $\mathrm{MB}$ concentration after light irradiation and $C_{o}$ represents the initial $M B$ concentration without light irradiation [30]. A plot of $C / C_{o}$ versus irradiation duration is presented in Figure 6d. For comparison, the photodegradation level of the MB solution containing various composites under dark conditions is also shown in Figure 6d. Notably, the $\mathrm{C} / \mathrm{C}_{\mathrm{o}}$ values for the degradation of the MB solution under dark conditions for 150 min were $7.9 \%$ and $4.3 \%$ for the NPT and NST, respectively. This reveals that the NPT possessed a higher MB dye surface adsorption capability. The relatively superior adsorption capability of the NPT enabled the MB molecules to diffuse freely inside the composites and facilitated more efficient contact between the photocatalysts and organic dyes, thus improving the resulting photodegradation level [27]. The photodegradation efficiency observed for the $\mathrm{TiO}_{2}-\mathrm{NiO}$ composites was substantially superior to that observed for the pristine $\mathrm{TiO}_{2}$. Contact between $\mathrm{p}-\mathrm{NiO}$ and $\mathrm{n}-\mathrm{TiO}_{2}$ in the composites engendered an inner electric field. The as-formed inner field further caused the photoexcited holes to flow into the negative field and the photoexcited electrons to move to the positive field in the oxides. Therefore, the photoexcited electron-hole pairs were separated more effectively by the $\mathrm{p}-\mathrm{n}$ junction formed in the $\mathrm{TiO}_{2}-\mathrm{NiO}$ composites than that formed in the pristine $\mathrm{TiO}_{2}$. This enabled the formation of more free carriers on the active sides of the composites and increased the photodegradation activity of the composites [31]. In addition, the NPT showed a higher degree of photodegradation than that of the NST. This study also applied the following formula to investigate the kinetics of the degradation of the $\mathrm{MB}$ solution containing various photocatalysts under light irradiation (Figure $6 \mathrm{e})$ : $\ln \left(\mathrm{C}_{\mathrm{o}} / \mathrm{C}\right)=$ $\mathrm{kt}$, where $\mathrm{k}$ is the apparent reaction rate constant and $\mathrm{t}$ is the irradiation duration [32]. Figure 6e shows a linear relationship between $\ln \left(\mathrm{C}_{\mathrm{o}} / \mathrm{C}\right)$ and irradiation duration. A higher degradation reaction rate was observed for the MB solution containing the NPT. The superior light-harvesting ability of the NPT accounted for the difference in photodegradation ability between the NPT and NST. The photodegradation stability of the $\mathrm{TiO}_{2}-\mathrm{NiO}$ composites under irradiation in the $\mathrm{MB}$ solution was evaluated after the recycling of the composites (Figure 6f,g). After three test cycles, the NST and NPT maintained relatively consistent activity without apparent deactivation.

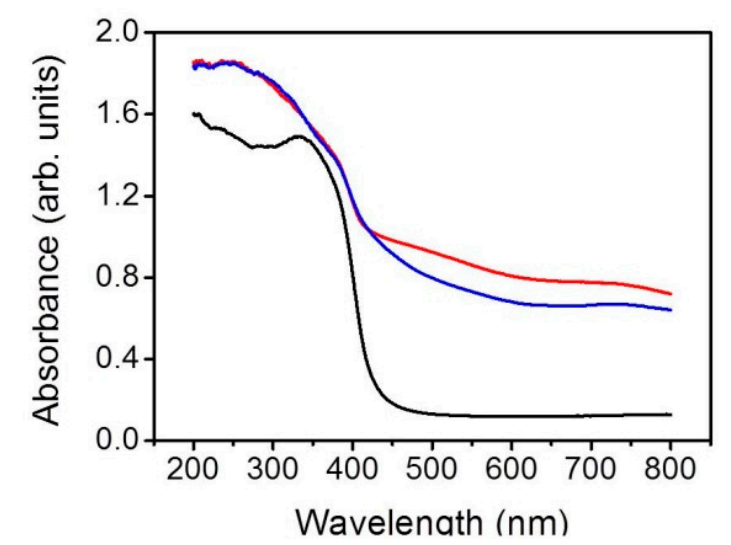

Figure 5. Optical absorbance spectra of the pristine $\mathrm{TiO}_{2}$ (black), NST (blue), and NPT (red). 

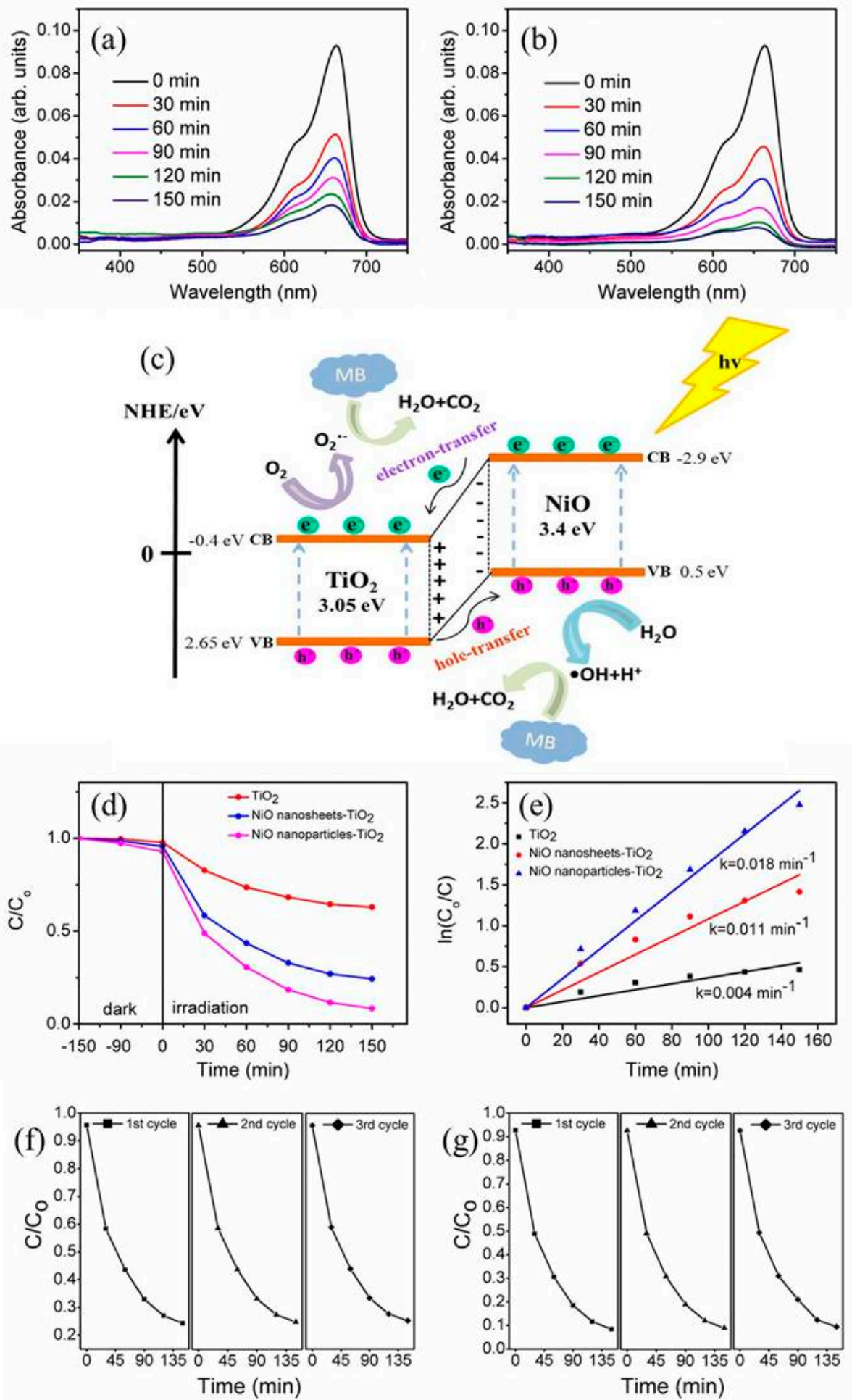

Figure 6. Intensity variation of absorbance spectra of the methylene blue (MB) solution vs. irradiation duration containing various $\mathrm{TiO}_{2}-\mathrm{NiO}$ composites under solar light irradiation: (a) NST. (b) NPT. (c) Schematic of photodegradation process of $\mathrm{TiO}_{2}-\mathrm{NiO}$ composites toward $\mathrm{MB}$. (d) The ratio of the remaining $\mathrm{MB}$ concentration after light irradiation $(\mathrm{C})$ and the initial $\mathrm{MB}$ concentration without light irradiation $\left(C_{0}\right)$ vs. irradiation time curves for the $\mathrm{MB}$ solution containing various $\mathrm{TiO}_{2}-\mathrm{NiO}$ composites in dark conditions and under light irradiation. (e) Plot of $\ln \left(\mathrm{C}_{\mathrm{o}} / \mathrm{C}\right)$ vs. reaction time for $\mathrm{MB}$ solution containing various $\mathrm{TiO}_{2}-\mathrm{NiO}$ composites under irradiation. (f, $\left.\mathbf{g}\right)$ Recycled performances of photodegradation of MB solution in the presence of the NST and NPT, respectively. 
Figure 7a,b present the gas response transients of the NST and NPT, respectively, toward 50, 100, 250,500 , and $750 \mathrm{ppm}$ acetone vapor at $300^{\circ} \mathrm{C}$. The gas-sensing response of the various composites increased with the acetone vapor concentration. As shown in Figure 7c, the gas-sensing response of the sensor comprising the NST increased from 31.3 to 145.5 when the acetone vapor concentration was increased from 50 to $750 \mathrm{ppm}$. By contrast, the gas-sensing responses of the sensor comprising the NPT were 10.2 and 22.8 with exposure to 50 and 750 ppm acetone vapor, respectively. The gas-sensing responses of the sensor comprising the NST were higher than those of the NPT under the given test conditions. Figure 7d,e show the results obtained from cyclic gas-sensing response tests of various $\mathrm{TiO}_{2}-\mathrm{NiO}$ composites on exposure to 250 ppm acetone vapor. The $\mathrm{TiO}_{2}-\mathrm{NiO}$ composites exhibited stability and reproducibility after five test cycles. For comparison, the gas-sensing responses of the pristine $\mathrm{TiO}_{2}$ exposed to 50 and 100 ppm acetone vapor are also displayed in Figure 7c. Decorating the surface of the $\mathrm{TiO}_{2}$ with $\mathrm{NiO}$ crystallites markedly improved the gas-sensing performance of the $\mathrm{TiO}_{2}$. For the pristine $\mathrm{TiO}_{2}$, the gas-sensing mechanism was explained mainly in terms of modulation of the depletion layer accompanying the adsorption and desorption of acetone molecules. When pristine $\mathrm{TiO}_{2}$ is exposed to air, oxygen molecules are adsorbed onto the surface of the $\mathrm{TiO}_{2}$ and are ionized to $\mathrm{O}^{-}$by capturing free electrons from the conduction band of $\mathrm{TiO}_{2}$. This reduces the electron concentration, which then leads to the formation of an electron depletion layer. $\mathrm{When}^{\mathrm{TiO}} \mathrm{O}_{2}$ is exposed to acetone vapor, the acetone molecules react with the surface-adsorbed oxygen species of $\mathrm{TiO}_{2}$ according to the following equation [33]: $\mathrm{CH}_{3} \mathrm{COCH}_{3 \text { (ads) }}+8 \mathrm{O}^{-}$(ads) $=3 \mathrm{CO}_{2}+3 \mathrm{H}_{2} \mathrm{O}+8 \mathrm{e}^{-}$. This reaction releases the trapped electrons back to the conduction band of $\mathrm{TiO}_{2}$, which increases the free-electron concentration, and ultimately reduces the resistance of the pristine $\mathrm{TiO}_{2}$. Notably, compared with the n-type gas-sensing behavior of pristine $\mathrm{TiO}_{2}$, the gas-sensing behavior of $\mathrm{TiO}{ }_{2}-\mathrm{NiO}$ composites changes to $\mathrm{p}$-type due to the $\mathrm{p}$-type nature of $\mathrm{NiO}$ shells. In $\mathrm{p}-\mathrm{n}$ oxide composites having a homogeneous $\mathrm{p}$-type shell layer coverage, the gas-sensing behavior is dominated by p-type shell layers [6,34]. The possible difference in the gas-sensing ability of the NST and NPT might be associated with surface defect density differences. The variations of both the surface and interfacial potential barriers of the composites were determined to dominate the gas-sensing behavior of the $\mathrm{TiO}_{2}-\mathrm{NiO}_{2}$ composites with various shell layer morphologies. Defect analyses revealed that the $\mathrm{NiO}$ nanosheets contained more surface crystal point defects than those of the $\mathrm{NiO}$ nanoparticles. An increase in oxygen-deficient regions in oxides can be contributed to more surface-chemisorbed oxygen species being able to participate in the oxidation-reduction reaction occurring on the surface of the sensing materials, which would thus induce a greater change in sensor resistance [21]. A higher number of oxygen-deficient regions on the surfaces of NST would increase the amount of surface-chemisorbed oxygen species. In $\mathrm{ZnO}-\mathrm{ZnCr}_{2} \mathrm{O}_{4}$ composites, a higher surface point defect density is highly associated with a higher sensing response toward ethanol vapor [35]. The structural analyses indicated that the $\mathrm{NiO}$ shell thicknesses of the composites were in the tens of nanometers; therefore, the interfacial potential barriers were assumed to be influenced by the surface adsorption and desorption of reductive acetone molecules. A larger potential barrier variation was expected in the NST than in the NPT during the gas-sensing tests. This explains the higher gas-sensing response of the NST in this study $[2,36]$. Moreover, the selectivity of the NST was shown in Figure 7f. A visible sensing response to acetone vapor of the NST was observed. Table 1 summarizes acetone vapor sensing responses of various $\mathrm{TiO}_{2}-\mathrm{NiO}$ composites reported in literatures for a comparison $[8,37,38]$. Notably, several reference works need a high operating temperature of $400{ }^{\circ} \mathrm{C}$ to obtain a visible gas-sensing response of $\mathrm{TiO}_{2}-\mathrm{NiO}$ composites. Comparatively, the NST herein exhibited superior acetone vapor sensing response and a relatively lower operating temperature. 


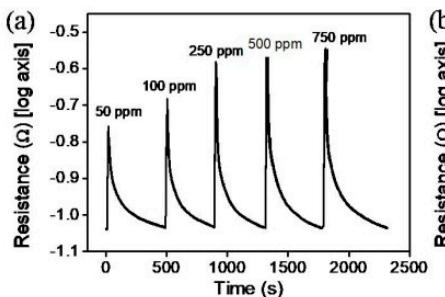

(d)

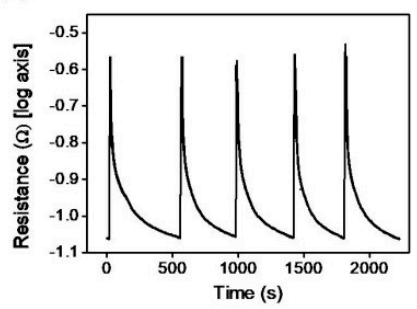

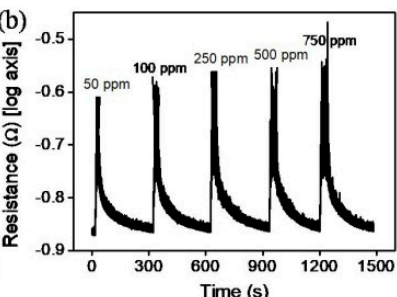

(e)

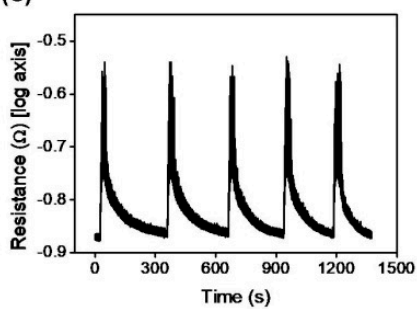

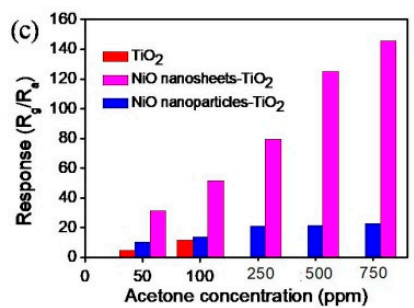

(f)

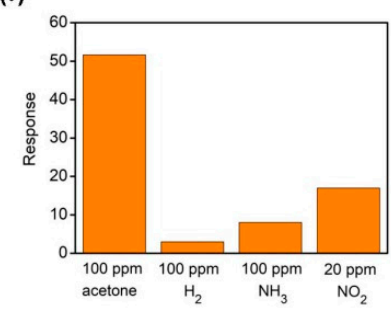

Figure 7. Gas-sensing response curves of various $\mathrm{TiO}_{2}-\mathrm{NiO}$ composites on exposure to various acetone vapor concentrations (50-750 ppm): (a) NST. (b) NPT. (c) Gas-sensing responses vs. acetone vapor concentrations for various $\mathrm{TiO}_{2}-\mathrm{NiO}$ composites. The gas sensing responses of the pristine $\mathrm{TiO}_{2}$ flowers to 50 and $100 \mathrm{ppm}$ acetone vapor are also shown for a comparison. (d,e) Cyclic gas-sensing response curves of the NST and NPT on exposure to $250 \mathrm{ppm}$ acetone vapor, respectively. (f) Gas-sensing selectivity of NST.

Table 1. Comparison of acetone vapor sensing responses of various $\mathrm{TiO}_{2}-\mathrm{NiO}$ composites $[8,37,38]$.

\begin{tabular}{|c|c|c|c|c|}
\hline Materials & $\begin{array}{l}\text { Operating } \\
\text { Temperature }\end{array}$ & $\begin{array}{c}\text { Acetone } \\
\text { Concentration }\end{array}$ & $\begin{array}{l}\text { Response }\left(R_{a} / R_{g}\right. \\
\left.\text { or } R_{g} / R_{a}\right)\end{array}$ & Reference \\
\hline $\mathrm{NiO}$ nanosheets- $\mathrm{TiO}_{2}$ flowers & $300^{\circ} \mathrm{C}$ & $100 \mathrm{ppm}$ & $51.6\left(R_{g} / R_{a}\right)$ & (this work) \\
\hline $\mathrm{NiO}$ nanoparticles- $\mathrm{TiO}_{2}$ flowers & $300^{\circ} \mathrm{C}$ & $100 \mathrm{ppm}$ & $13.54\left(\mathrm{R}_{\mathrm{g}} / \mathrm{R}_{\mathrm{a}}\right)$ & (this work) \\
\hline $\mathrm{TiO}_{2}-\mathrm{NiO}$ nanorod & $400{ }^{\circ} \mathrm{C}$ & 200 ppm & $9.81\left(\mathrm{R}_{\mathrm{g}} / \mathrm{R}_{\mathrm{a}}\right)$ & [37] \\
\hline $\mathrm{TiO}_{2}-\mathrm{NiO}$ nanorod & $400{ }^{\circ} \mathrm{C}$ & $200 \mathrm{ppm}$ & $9.33\left(R_{a} / R_{g}\right)$ & [8] \\
\hline $\begin{array}{c}95 \mathrm{wt} \% \mathrm{TiO}_{2}-5 \mathrm{wt} \% \mathrm{NiO} \text { composite } \\
\text { film }\end{array}$ & $300^{\circ} \mathrm{C}$ & 100 ppm & $6\left(R_{g} / R_{a}\right)$ & [38] \\
\hline $\begin{array}{c}99 \mathrm{wt} \% \mathrm{TiO}_{2}-1 \mathrm{wt} \% \mathrm{NiO} \text { composite } \\
\text { film }\end{array}$ & $400^{\circ} \mathrm{C}$ & 100 ppm & $6.5\left(\mathrm{R}_{\mathrm{g}} / \mathrm{R}_{\mathrm{a}}\right)$ & [38] \\
\hline
\end{tabular}

\section{Conclusions}

$\mathrm{TiO}_{2}-\mathrm{NiO}$ heterostructures were successfully synthesized by combining a hydrothermal process and a chemical bath deposition method. Crystalline $\mathrm{TiO}_{2}-\mathrm{NiO}$ heterostructures were formed after post-annealing procedures, and the surface features of the $\mathrm{TiO}_{2}-\mathrm{NiO}$ heterostructures were controlled by varying the post-annealing temperature. Photocatalytic activity tests revealed that the NPT had a higher surface adsorption capability for MB dyes and light harvesting ability when compared with the NST. These factors accounted for the superior photocatalytic activity of the NPT. By contrast, gas sensors made from the $\mathrm{TiO}_{2}-\mathrm{NiO}$ heterostructures exhibited strong gas-sensing responses and recycling stability to acetone vapor. The NST exhibited a higher gas-sensing response than that of the NPT when exposed to acetone vapor under the given test conditions. The NiO nanosheets comprised more surface crystal point defects than the $\mathrm{NiO}$ nanoparticles did, which engendered the difference in potential barrier variation in the $\mathrm{TiO}_{2}-\mathrm{NiO}$ heterostructures with various surface morphologies during gas-sensing tests.

Author Contributions: Methodology, N.-C.X.; formal analysis, N.-C.X., K.-J.C.; investigation, N.-C.X., K.-J.C.; writing-original draft preparation, Y.-C.L.; supervision, Y.-C.L.; writing-review and editing, Y.-C.L.

Funding: This research was funded by Ministry of Science and Technology of Taiwan. Grant No. MOST 108-2221-E-019-034-MY3.

Conflicts of Interest: The authors declare no conflict of interest. 


\section{References}

1. Luna-Flores, A.; Sosa-Sánchez, J.L.; Morales-Sánchez, M.A.; Agustín-Serrano, R.; Luna-López, J.A. An Easy-Made, Economical and Efficient Carbon-Doped Amorphous $\mathrm{TiO}_{2}$ Photocatalyst Obtained by Microwave Assisted Synthesis for the Degradation of Rhodamine B. Materials 2017, 10, 1447. [CrossRef] [PubMed]

2. Liang, Y.C.; Xu, N.C.; Wang, C.C.; Wei, D.H. Fabrication of Nanosized Island-Like CdO Crystallites-Decorated $\mathrm{TiO}_{2}$ Rod Nanocomposites via a Combinational Methodology and Their Low-Concentration $\mathrm{NO}_{2}$ Gas-Sensing Behavior. Materials 2017, 10, 778. [CrossRef] [PubMed]

3. Liang, Y.C.; Wang, C.C. Hydrothermally derived zinc sulfide sphere-decorated titanium dioxide flower-like composites and their enhanced ethanol gas-sensing performance. J. Alloy Compd. 2018, 730, 333-341. [CrossRef]

4. Zhang, H.; Yu, M.; Qin, X. Photocatalytic Activity of $\mathrm{TiO}_{2}$ Nanofibers: The Surface Crystalline Phase Matters. Nanomaterials 2019, 9, 535. [CrossRef] [PubMed]

5. Li, Y.; Wang, W.; Wang, F.; Di, L.; Yang, S.; Zhu, S.; Yao, Y.; Ma, C.; Dai, B.; Yu, F. Enhanced Photocatalytic Degradation of Organic Dyes via Defect-Rich $\mathrm{TiO}_{2}$ Prepared by Dielectric Barrier Discharge Plasma. Nanomaterials 2019, 9, 720. [CrossRef]

6. Liang, Y.C.; Liu, Y.C. Design of Nanoscaled Surface Morphology of $\mathrm{TiO}_{2}-\mathrm{Ag}_{2} \mathrm{O}$ Composite Nanorods through Sputtering Decoration Process and Their Low-Concentration $\mathrm{NO}_{2}$ Gas-Sensing Behaviors. Nanomaterials 2019, 9, 1150. [CrossRef]

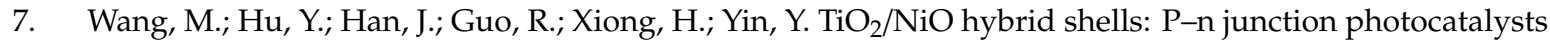
with enhanced activity under visible light. J. Mater. Chem. A 2015, 3, 20727-20735. [CrossRef]

8. Sun, G.J.; Kheel, H.; Park, S.; Lee, S.; Park, S.E.; Lee, C. Synthesis of $\mathrm{TiO}_{2}$ nanorods decorated with $\mathrm{NiO}$ nanoparticles and their acetone sensing properties. Ceram. Int. 2016, 42, 1063-1069. [CrossRef]

9. Liu, X.; Li, Y.; Yang, J.; Wang, B.; Ma, M.; Xu, F.; Sun, R.; Zhang, X. Enhanced Photocatalytic Activity of CdS-Decorated $\mathrm{TiO}_{2} /$ Carbon Core-Shell Microspheres Derived from Microcrystalline Cellulose. Materials 2016, 9, 245. [CrossRef]

10. Ha, M.N.; Zhu, F.; Liu, Z.; Wang, L.; Liu, L.; Lu, G.; Zhao, Z. Morphology-controlled synthesis of $\mathrm{SrTiO}_{3} / \mathrm{TiO}_{2}$ heterostructures and their photocatalytic performance for water splitting. RSC Adv. 2016, 6, 21111-21118. [CrossRef]

11. Wang, M.; Cui, L.; Li, S.; Li, Z.; Ma, T.; Luan, G.; Liu, W.; Zhang, F. Facile fabrication hybrids of TiO ${ }_{2} @ Z n O$ tubes with enhanced photocatalytic properties. RSC Adv. 2016, 6, 58452-58457. [CrossRef]

12. Fujii, E.; Tomozawa, A.; Torii, H.; Takayama, R. Preferred Orientations of NiO Films Prepared by Plasma-Enhanced Metalorganic Chemical Vapor Deposition. Jpn. J. Appl. Phys. 1996, 35, L328-L330. [CrossRef]

13. Eskandarloo, H.; Badiei, A.; Haug, C. Enhanced photocatalytic degradation of an azo textile dye by using $\mathrm{TiO}_{2} / \mathrm{NiO}$ coupled nanoparticles: Optimization of synthesis and operational key factors. Mater. Sci. Semicond. Process. 2014, 27, 240-253. [CrossRef]

14. Kaye, S.S.; Long, J.R. Hydrogen Storage in the Dehydrated Prussian Blue Analogues $\mathrm{M}_{3}\left[\mathrm{Co}(\mathrm{CN})_{6}\right]_{2}(\mathrm{M}=$ $\mathrm{Mn}, \mathrm{Fe}, \mathrm{Co}, \mathrm{Ni}, \mathrm{Cu}, \mathrm{Zn})$. J. Am. Chem. Soc. 2005, 127, 6506-6507. [CrossRef]

15. Gaspera, E.D.; Guglielmi, M.; Agnoli, S.; Granozzi, G.; Post, M.L.; Bello, V.; Mattei, G.; Martucci, A. Au Nanoparticles in Nanocrystalline $\mathrm{TiO}_{2}-\mathrm{NiO}$ Films for SPR-Based, Selective $\mathrm{H}_{2} \mathrm{~S}$ Gas Sensing. Chem. Mater. 2010, 22, 3407-3417. [CrossRef]

16. Mishra, Y.K.; Adelung, R. ZnO tetrapod materials for functional applications. Mater. Today 2018, 21, 631-651. [CrossRef]

17. Tian, H.; Fan, H.; Dong, G.; Ma, L.; Ma, J. NiO/ZnO p-n heterostructures and their gas sensing properties for reduced operating temperature. RSC Adv. 2016, 6, 109091-109098. [CrossRef]

18. Liang, K.; Tang, X.; Hu, W. High-performance three-dimensional nanoporous $\mathrm{NiO}$ film as a supercapacitor electrode. J. Mater. Chem. 2012, 22, 11062-11067. [CrossRef]

19. Varghese, B.; Reddy, M.V.; Yanwu, Z.; Chang, S.L.; Hoong, T.C.; Rao, G.V.S.; Chowdari, B.V.R.; Wee, A.T.S.; Lim, C.T.; Sow, C.-H. Fabrication of NiO Nanowall Electrodes for High Performance Lithium Ion Battery. Chem. Mater. 2008, 20, 3360-3367. [CrossRef]

20. Li, D.; Zhang, Y.; Liu, D.; Yao, S.; Liu, F.; Wang, B.; Sun, P.; Gao, Y.; Chuai, X.; Lu, G. Hierarchical core/shell $\mathrm{ZnO} / \mathrm{NiO}$ nanoheterojunctions synthesized by ultrasonic spray pyrolysis and their gas-sensing performance. CrystEngComm 2016, 18, 8101-8107. [CrossRef] 
21. Wang, C.; Cui, X.; Liu, J.; Zhou, X.; Cheng, X.; Sun, P.; Hu, X.; Li, X.; Zheng, J.; Lu, G. Design of Superior Ethanol Gas Sensor Based on Al-Doped NiO Nanorod-Flowers. ACS Sens. 2016, 1, 131-136. [CrossRef]

22. Ibupoto, Z.H.; Abbasi, M.A.; Liu, X.; AlSalhi, M.S.; Willander, M. The Synthesis of NiO/TiO ${ }_{2}$ Heterostructures and Their Valence Band Offset Determination. J. Nanomater. 2014, 6, 928658. [CrossRef]

23. Lin, J.; Shen, J.; Wang, R.; Cui, J.; Zhou, W.; Hu, P.; Liu, D.; Liu, H.; Wang, J.; Boughton, R.I.; et al. Nano-p-n junctions on surface-coarsened $\mathrm{TiO}_{2}$ nanobelts with enhanced photocatalytic activity. J. Mater. Chem. 2011, 21,5106-5113. [CrossRef]

24. Guo, J.; Fu, W.; Yang, H.; Yu, Q.; Zhao, W.; Zhou, X.; Sui, Y.; Ding, J.; Li, Y.; Cheng, S.; et al. A NiO/TiO 2 junction electrode constructed using self-organized $\mathrm{TiO}_{2}$ nanotube arrays for highly efficient photoelectrocatalytic visible light activations. J. Phys. D Appl. Phys. 2010, 43, 245202. [CrossRef]

25. Uddin, M.T.; Nicolas, Y.; Olivier, C.; Jaegermann, W.; Rockstroh, N.; Junge, H.; Toupance, T. Band alignment investigations of heterostructure $\mathrm{NiO} / \mathrm{TiO}_{2}$ nanomaterials used as efficient heterojunction earth-abundant metal oxide photocatalysts for hydrogen production. Phys. Chem. Chem. Phys. 2017, 19, 19279-19288. [CrossRef] [PubMed]

26. Zhang, H.; Liu, X.; Li, Y.; Sun, Q.; Wang, Y.; Wood, B.J.; Liu, P.; Yang, D.; Zhao, H. Vertically aligned nanorod-like rutile $\mathrm{TiO}_{2}$ single crystal nanowire bundles with superior electron transport and photoelectrocatalytic properties. J. Mater. Chem. 2012, 22, 2465-2472. [CrossRef]

27. Sun, B.; Zhou, G.; Gao, T.; Zhang, H.; Yu, H. NiO nanosheet $/ \mathrm{TiO}_{2}$ nanorod-constructed $\mathrm{p}-\mathrm{n}$ heterostructures for improved photocatalytic activity. Appl. Surf. Sci. 2016, 364, 322-331. [CrossRef]

28. Lin, H.; Ye, H.; Chen, S.; Chen, Y. One-pot hydrothermal synthesis of $\mathrm{BiPO}_{4} / \mathrm{BiVO}_{4}$ with enhanced visible-light photocatalytic activities for methylene blue degradation. RSC Adv. 2014, 4, 10968-10974. [CrossRef]

29. Liang, Y.C.; Lung, T.W. Growth of Hydrothermally Derived CdS-Based Nanostructures with Various Crystal Features and Photoactivated Properties. Nanoscale Res. Lett. 2016, 11, 264. [CrossRef]

30. Liang, Y.C.; Lo, Y.R.; Wang, C.C.; Xu, N.C. Shell Layer Thickness-Dependent Photocatalytic Activity of Sputtering Synthesized Hexagonally Structured ZnO-ZnS Composite Nanorods. Materials 2018, 11, 87. [CrossRef]

31. Liang, Y.C.; Liu, Y.C.; Hung, C.S. Sputtering control of $\mathrm{Ag}_{2} \mathrm{O}$ decoration configurations on $\mathrm{ZnO}$ nanorods and their surface arrangement effects on photodegradation ability toward methyl orange. Nanotechnology 2019, 30, 495701-495711. [CrossRef] [PubMed]

32. Liang, Y.C.; Chung, C.C.; Lin, T.Y.; Cheng, Y.R. Synthesis and microstructure-dependent photoactivated properties of three-dimensional cadmium sulfide crystals. J. Alloy Compd. 2016, 688, 769-775. [CrossRef]

33. Liang, Y.C.; Cheng, Y.R.; Hsia, H.Y.; Chung, C.C. Fabrication and reducing gas detection characterization of highly-crystalline p-type zinc chromite oxide thin film. Appl. Surf. Sci. 2016, 364, 837-842. [CrossRef]

34. Kim, H.J.; Jeong, H.M.; Kim, T.H.; Chung, J.H.; Kang, Y.C.; Lee, J.H. Enhanced Ethanol Sensing Characteristics of $\mathrm{In}_{2} \mathrm{O}_{3}$-Decorated NiO Hollow Nanostructures via Modulation of Hole Accumulation Layers. ACS Appl. Mater. Interfaces 2014, 6, 18197-18204. [CrossRef] [PubMed]

35. Liang, Y.C.; Hsia, H.Y.; Cheng, Y.R.; Lee, C.M.; Liu, S.L.; Lin, T.Y.; Chung, C.C. Crystalline quality-dependent gas detection behaviors of zinc oxide-zinc chromite p-n heterostructures. CrystEngComm 2015, 17, 4190-4199. [CrossRef]

36. Liang, Y.C.; Lo, Y.J. High-temperature solid-state reaction induced structure modifications and associated photoactivity and gas-sensing performance of binary oxide one-dimensional composite system. RSC Adv. 2017, 7, 29428-29439. [CrossRef]

37. Sun, G.J.; Kheel, H.; Choi, S.; Hyun, S.K.; Lee, C. Prominent Gas Sensing Performance of $\mathrm{TiO}_{2}$-Core/NiO-Shell Nanorod Sensors. J. Nanosci. Nanotechnol. 2017, 17, 4099-4102. [CrossRef]

38. Wisitsoraat, A.; Tuantranont, A.; Comini, E.; Sberveglieri, G.; Wlodarski, W. Characterization of n-type and p-type semiconductor gas sensors based on $\mathrm{NiO}_{x}$ doped $\mathrm{TiO}_{2}$ thin films. Thin Solid Films 2009, 517, 2775-2780. [CrossRef]

(C) 2019 by the authors. Licensee MDPI, Basel, Switzerland. This article is an open access article distributed under the terms and conditions of the Creative Commons Attribution (CC BY) license (http://creativecommons.org/licenses/by/4.0/). 